02,13

\title{
Исследование параметров сверхпроводящих и изолирующих элементов структур, получаемых на пленках ҮВСО методом задающей маски, при уменьшении их размеров
}

\author{
() Д.В. Мастеров., С.А. Павлов, А.Е. Парафин, Е.В. Скороходов \\ Институт фризики микроструктур РАН, ФИЦ Институт прикладной физики РАН, \\ Нижний Новгород, Россия \\ E-mail: parafin@ipmras.ru
}

Поступила в Редакцию 9 апреля 2021 г.

В окончательной редакции 9 апреля 2021 г.

Принята к публикации 19 апреля 2021 г.

\begin{abstract}
Настоящая работа посвящена исследованию электрофизических параметров сверхпроводящих и изолирующих элементов планарных структур, изготавливаемых методом задающей маски на основе высокотемпературного сверхпроводника $\mathrm{YBa}_{2} \mathrm{Cu}_{3} \mathrm{O}_{7-d}$, при уменьшении размеров элементов до значений порядка одного микрометра. С использованием стандартной фотолитографии методом задающей маски получены структуры со сверхпроводящими элементами шириной $2 \mu \mathrm{m}$ и параметрами, достаточными для приборных применений.
\end{abstract}

Ключевые слова: нано- и микроструктуры, дефекты, рост в локальных областях, ҮВСО.

DOI: 10.21883/FTT.2021.09.51241.10H

\section{1. Введение}

Формирование топологии схемы является критически важным этапом при изготовлении планарных структур на основе пленок высокотемпературного сверхпроводника $\mathrm{YBa}_{2} \mathrm{Cu}_{3} \mathrm{O}_{7-d}(\mathrm{YBCO})$, который существенно влияет на их конечные параметры. Это связано с высокой чувствительностью свойств пленок ҮВСО к внешним воздействиям. Топологию структур на основе пленок YВСО формируют различными способами: ионным травлением $[1,2]$, ионной имплантацией $[3,4]$, химическим травлением. Общим во всех указанных методах, несмотря на большое количество модификаций, является то, что сначала на всю поверхность подложки осаждается сверхпроводящая пленка ҮВСО, а затем формируется топология сверхпроводящего устройства. Авторами настоящей статьи предложен и развивается метод задающей маски (3М) для изготовления планарных структур на основе пленок ҮВСО. По сравнению с другими методами получения ҮВСО-структур данный метод имеет ряд преимуществ [5-8]. Так как рост пленки является завершающим этапом формирования всей структуры, то при формировании структур исключаются операции травления ҮВСО или ионной имплантации, поэтому негативное воздействие на пленку ҮВСО в данном случае минимально. Имеется возможность проводить многократные циклы осаждения ҮВСО, последовательно увеличивая толщину сверхпроводящих элементов, положение и топология которых фиксированы. Осаждение YВСО происходит в локальные области - окна задающей маски, и узкие элементы структуры могут быть полностью свободны от дефектов, таких как преципитаты $\mathrm{CuO}$ и др. В настоящей работе проводится дальнейшее исследование возможностей технологии на основе 3М для создания топологии сверхпроводящих схем. Основная цель работы - определение минимальных размеров сверхпроводящих элементов и изолирующих областей, воспроизводимо получаемых методом 3М.

\section{2. Исследование возможности получения методом 3М сверхпроводящих ҮВСО-мостиков микронных размеров}

Тестовые структуры на основе пленок высокотемпературного сверхпроводника ҮВСО изготавливались на подложках двух типов. В первом случае использовались сапфировые подложки без подслоя. В этом случае применялась т.н். двухслойная 3М: на подложку с маской из тонкого, толщиной около $100 \mathrm{~nm}$, аморфного оксида церия, осажденного без нагрева подложки $\left(\mathrm{coldCeO}_{2}\right)$, при температуре эпитаксиального роста осаждается оксид церия толщиной $50 \mathrm{~nm}$. В результате подслой эпитаксиального оксида церия $\left(\mathrm{epiCeO}_{2}\right)$ образуется только в окнах рисунка coldCeO 2 , в которых далее формируются сверхпроводящие элементы, в областях вне окон с подслоем еріСеО 2 формируются изолирующие области.

Во втором случае использовались сапфировые подложки с предварительно нанесенным подслоем эпитаксиального оксида церия $\left(\mathrm{ALO}+\mathrm{epiCeO}_{2}\right)$. В отличие от чистого сапфира, такие подложки сходны с другими стандартными подложками для структур на основе YВСО. В этом случае применялась т. н. однослойная 3М, состоящая из толстого, около $1.5 \mu \mathrm{m}$, слоя аморфного оксида церия cold $\mathrm{CeO}_{2}[9]$. 


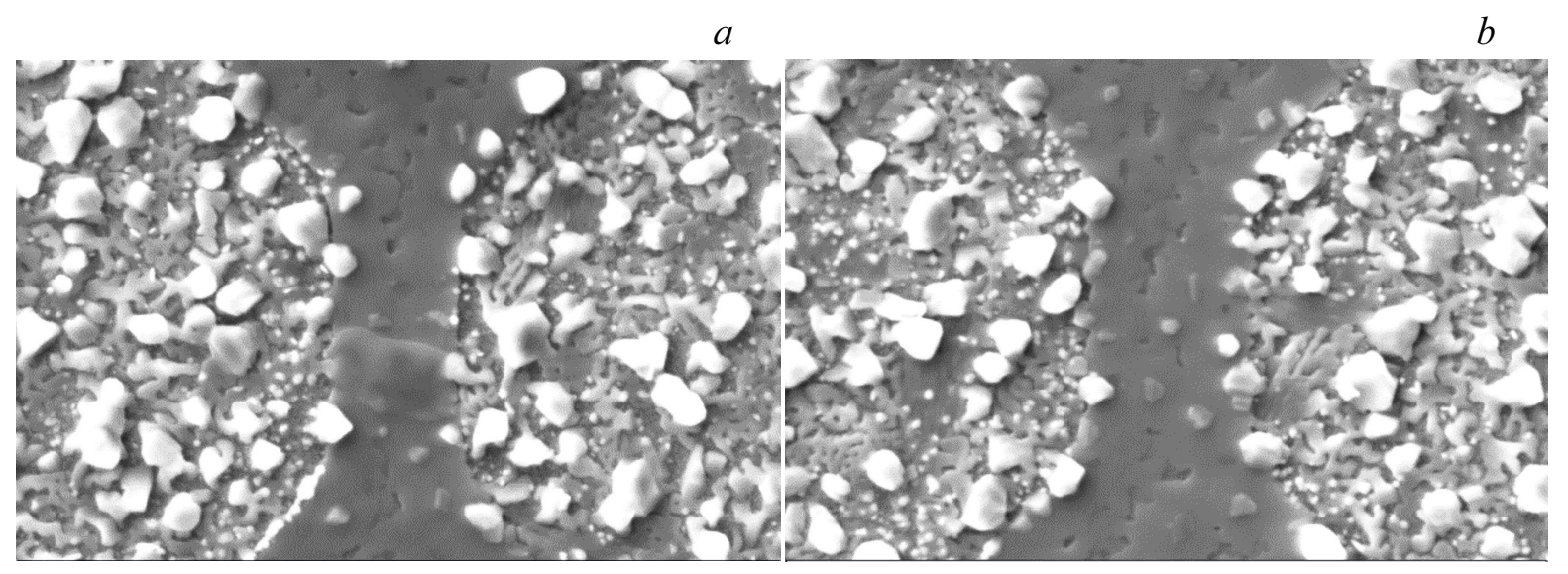

Рис. 1. Изображение во вторичных электронах мостиков, изготовленных методом двухслойной задающей маски (образец № MP 3.347). Ширина мостиков на фотографии: (a) $1.88 \mu \mathrm{m},(b) 2.4 \mu \mathrm{m}$; увеличение 80000 . Дефект на более узком мостике результат пробоя при измерении электрических параметров.

В обоих случаях формирование маски из аморфного оксида церия проводилось методом взрывной фотолитографии (lift-off). Для проведения фотолитографии использовалась установка совмещения и экспонирования MJB4 с оптикой UV400 $(\lambda=350-400 \mathrm{~nm})$. Уход размеров относительно фотошаблона составил $0.3-0.5 \mu \mathrm{m}$ в одну сторону. В нашем случае уход размеров происходит уже на фоторезисте на этапе получения рисунка для формирования 3М и связан с особенностью формирования рисунка на прозрачных подложках.

После формирования 3М на подложку осаждается слой YВСО при температуре эпитаксиального роста. В результате в окнах маски, т.е. на эпитаксиальном $\mathrm{CeO}_{2}$, формируются сверхпроводящие элементы заданного рисунка, а между ними - разделительные области.

В таблице представлены параметры тестовых сверхпроводящих мостиков различной ширины - от 2.0 до $10.5 \mu \mathrm{m}$, изготовленных методом двухслойной ЗМ. Измерения ширины мостиков проводились на оптическом микроскопе, погрешность измерения составляла не более $0.2 \mu \mathrm{m}$. Электрофизические измерения выполнялись

Параметры тестовых сверхпроводящих элементов микронной ширины (двухслойная 3М, образец № MP 3.347, толщина пленки YВСО $110 \mathrm{~nm}): w$ - измеренная ширина мостика, $T_{c}$ - температура, при которой напряжение на мостике обращается в ноль, $I_{c}$ - критический ток сверхпроводящего мостика при температуре $T=77 \mathrm{~K}, J_{c}$ - плотность критического тока мостика при $T=77 \mathrm{~K}, \gamma-$ отношение измеренных сопротивлений мостиков при $T=300 \mathrm{~K}$ и $T=100 \mathrm{~K}$

\begin{tabular}{c|c|c|c|c}
\hline$w, \mu \mathrm{m}$ & $T_{c}, \mathrm{~K}$ & $I_{c}, \mathrm{~mA}$ & $J_{c}, \mathrm{MA} / \mathrm{cm}^{2}$ & $\gamma$ \\
\hline 2.0 & 87.6 & 7.3 & 3.3 & 2.92 \\
2.7 & 87.7 & 8.6 & 2.9 & 2.92 \\
4.8 & 88.3 & 14.7 & 2.8 & 2.92 \\
10.5 & 88.9 & 38 & 3.3 & 2.93
\end{tabular}

четырехзондовым методом в жидком азоте. Характерные фотографии мостиков, полученные на электронном микроскопе, приведены на рис. 1. Изображения поверхности структур были получены на электронных микроскопах SUPRA 50VP и EVO-10.

Параметры мостиков, изготовленных с использованием однослойной маски, в пределах ошибки измерений совпадают с представленными в таблице.

Как видно из таблицы, критическая температура для всех мостиков составляет $\sim 88 \mathrm{~K}$, плотность критического тока - приблизительно $3 \mathrm{MA} / \mathrm{cm}^{2}$ при $T=77 \mathrm{~K}$. Разброс плотности критического тока для тестовых мостиков шириной от 2 до $10 \mu \mathrm{m}$ составляет величину меньше чем $10 \%$, а разброс температуры сверхпроводящего перехода - меньше $0.5 \mathrm{~K}$. Это свидетельствует о высоком качестве сверхпроводящей области и воспроизводимости характеристик структур микронных размеров, получаемых методом 3М, при использовании стандартной оптической фотолитографии.

\section{3. Изолирующие области в ҮВСО-структурах, получаемые методом однослойной задающей маски}

В работе [9] нами была проведена оценка изолирующих свойств разделительных областей, полученных методом задающей маски, по измерениям сопротивления между соседними чипами сверхпроводящей структуры. Расстояние между чипами составляло $200 \mu \mathrm{m}$. В настоящей работе мы рассмотрели возможность формирования методом 3М изолирующих разделительных областей микронных размеров. Для этого были изготовлены структуры со сверхпроводящими мостиками, пересеченными изолирующими полосками с шириной вплоть до $1 \mu \mathrm{m}$. 
$a$



Рис. 2. Изображение во вторичных электронах изолирующей области (однослойная маска, образец № МР 3.267, чип № 1-2). Ширина мостика $4 \mu \mathrm{m}$, ширина изолирующей полоски, пересекающей мостик, $1.4 \mu \mathrm{m}$; (a) увеличение $5000,(b)$ увеличение 15500 .

$a$

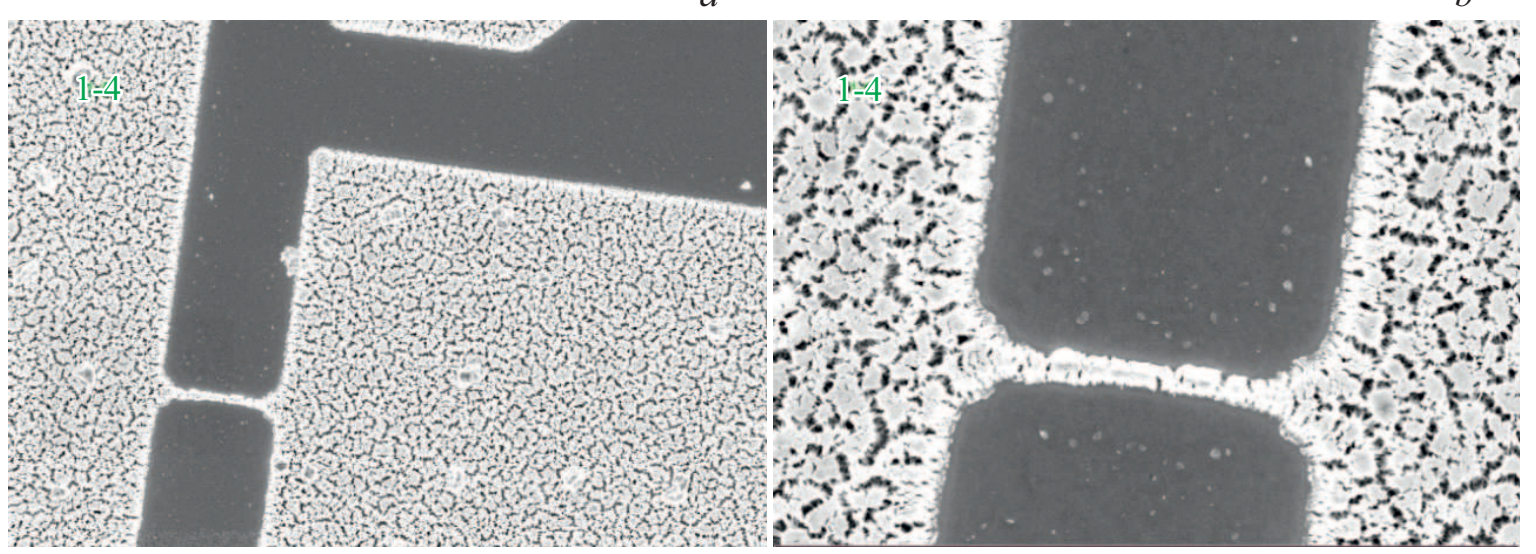

Рис. 3. Изображение во вторичных электронах изолирующей области (однослойная маска, образец № МР 3.267, чип № 1-4). Ширина мостика $10 \mu \mathrm{m}$, ширина изолирующей полоски, пересекающей мостик, $1 \mu \mathrm{m}$; $(a)$ увеличение $5000,(b)$ увеличение 15500 .

Характерные изображения узкой изолирующей области (однослойная 3М), пересекающей мостик на образце № MP 3.267 (толщина YВСО $130 \mathrm{~nm}$ ), полученные на электронном микроскопе, приведены на рис. 2. (чип № 1-2) и на рис. 3 (чип № 1-4).

Измеренное на чипе № 1-2 сопротивление между двумя частями сверхпроводящего мостика, разделенными изолирующей полоской составило при комнатной температуре величину $550 \mathrm{k} \Omega$, при температуре жидкого азота - $150 \mathrm{M} \Omega$ (предельная величина, доступная нашей измерительной системе). Так как измеренное сопротивление представляет собой параллельно включенные сопротивление изолирующей полоски, пересекающей мост, и сопротивление утечки по изолирующей области, окружающей чип, можно констатировать, что сопротивление изолирующей полоски выше измеренных значений сопротивления. Количество квадратов изолирующей области шириной $1.4 \mu \mathrm{m}$ на чипе № 1-2 оценим как 1 квадрат. В результате получим оценку сопротивления узкого участка изолирующей области не менее чем $550 \mathrm{k} \Omega$ на квадрат при комнатной температуре и не менее чем $150 \mathrm{M} \Omega$ на квадрат при $T=77 \mathrm{~K}$.

Измеренное на чипе № 1-4 сопротивление между областями сверхпроводящего мостика, разделенными изолирующей полоской составило при комнатной температуре величину $250 \mathrm{k} \Omega$ и при температуре жидкого азота - $150 \mathrm{M} \Omega$. Количество квадратов изолирующей области шириной $1 \mu \mathrm{m}$ оценим (см. рис. 3 ), как 1/8 квадрата. В результате получим оценку сопротивления узкого участка изолирующей области не менее чем $4 \mathrm{M} \Omega$ на квадрат при комнатной температуре и $1.2 \mathrm{G} \Omega$ на квадрат при $T=77 \mathrm{~K}$.

На основании изложенного можно констатировать, что сопротивление изолирующей области шириной вплоть до $1 \mu \mathrm{m}$, получаемой в структуре ҮВСО с использованием однослойной задающей маски из аморфного оксида церия толщиной $1.5 \mu \mathrm{m}$, составляет минимум $550 \mathrm{k} \Omega$ на квадрат при комнатной температуре и минимум $150 \mathrm{M} \Omega$ на квадрат при $T=77 \mathrm{~K}$. 


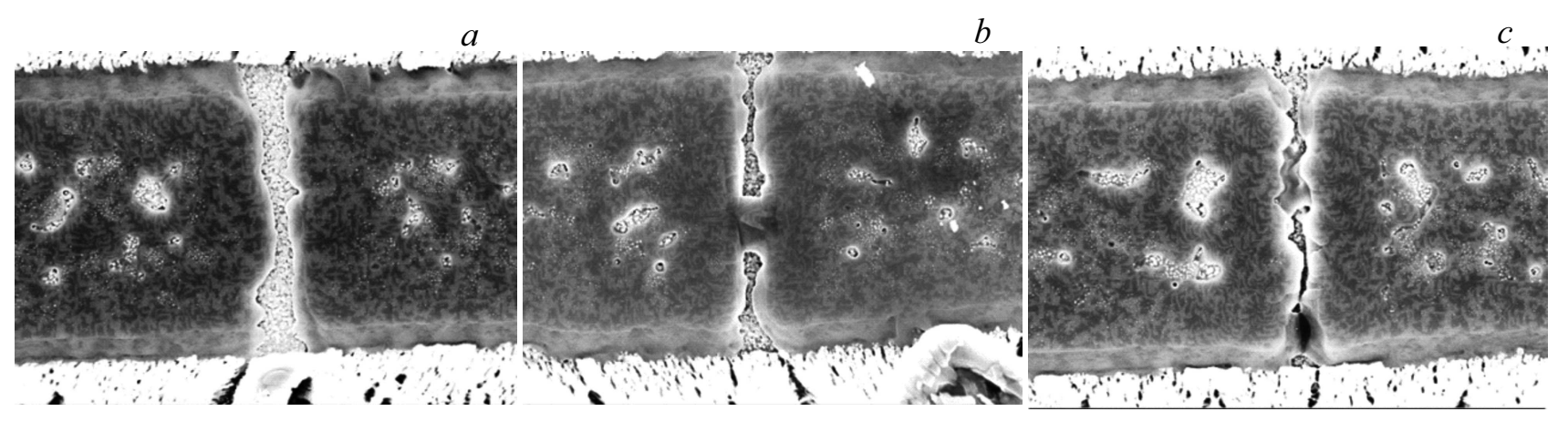

Рис. 4. Изображение во вторичных электронах изолирующей области на образце № MP 3.268 (двухслойная маска) с первым слоем аморфного оксида церия $100 \mathrm{~nm}(a), 30 \mathrm{~nm}(b), 10 \mathrm{~nm}(c)$. Ширина мостика $4 \mu \mathrm{m}$, ширина изолирующей полоски менее $1 \mu \mathrm{m}$. Увеличение 50000 .

\section{4. Изолирующие области в ҮВСО-структурах, получаемые методом двухслойной задающей маски}

Для определения характеристик изолирующей области, получаемой при использовании двухслойной задающей маски, была изготовлена структура № MP 3.268. Особенностью данной структуры является то, что для ее формирования использовались как двухслойная, так и однослойная задающие маски. Сначала методом двухслойной (с первым слоем cold $\mathrm{CeO}_{2}$ ) задающей маски были сформированы узкие полоски шириной $1 \mu \mathrm{m}$, в которых при напылении ҮВСО образуется исследуемая изолирующая область. Причем на одном образце на разных участках толщина слоя coldCeO $\mathrm{O}_{2}$ составила 10,30 и $100 \mathrm{~nm}$. Для формирования топологии моста использовалась однослойная маска coldCeO $\mathrm{C}_{2}$ толщиной $1.5 \mu \mathrm{m}$. Далее на полученную структуру было проведено осаждение YВСО в режиме эпитаксиального роста толщиной сначала $130 \mathrm{~nm}$, а затем еще $100 \mathrm{~nm}$. После каждого осаждения ҮВСО проводились электрофизические измерения структуры.

Характерные фотографии узких изолирующих областей (двухслойная $3 \mathrm{M}$ ) с разной толщиной первого слоя coldCeO $\mathrm{C}_{2}$, пересекающих мостики шириной $4 \mu \mathrm{m}$ на образце № MP 3.268, полученные в электронном микроскопе, приведены на рис. 4.

При толщине слоя ҮВСО $130 \mathrm{~nm}$ на образце № MP 3.268 сопротивление мостиков, пересеченных изолирующей полоской, полученной с использованием двухслойной маски с первым слоем из аморфного оксида церия толщиной $100 \mathrm{~nm}$, при комнатной температуре составило величину от 910 до $3.4 \mathrm{M} \Omega$ (корреляции с шириной мостика не обнаружено), при $T=77 \mathrm{~K}$ величину не менее чем $150 \mathrm{M} \Omega$. Для толщины слоя аморфного оксида церия $30 \mathrm{~nm}$ сопротивление при комнатной температуре было от 120 до $290 \Omega$, а при $T=77 \mathrm{~K}$ на одном из мостиков появилась сверхпроводящая „закоротка“. При минимальной толщине аморфного оксида церия $-10 \mathrm{~nm}-$ сопротивление мостиков при комнатной температуре составило $110-660 \Omega$, при $T=77 \mathrm{~K}$ сопротивление мостика шириной $7 \mu \mathrm{m}$ составило $4.4 \Omega$.

После допыления слоя ҮВСО на структуру № МP 3.268 его толщина составила $230 \mathrm{~nm}$. При этом сопротивление всех пересеченных мостиков на образце при комнатной температуре уменьшилось. При $T=77 \mathrm{~K}$ и толщинах аморфного оксида церия 10 и $30 \mathrm{~nm}$ в мостиках появились сверхпроводящие „закоротки“, а при толщине аморфного оксида церия $100 \mathrm{~nm}$ сопротивление пересеченных мостиков в жидком азоте составило величину не менее чем $150 \mathrm{M} \Omega$. Возникновение сверхпроводящих „закороток“ в мостике связано, возможно, со срастанием ҮВСО через изолирующую полоску, когда высота слоя ҮВСО превышает высоту двухслойной задающей маски (см. рис. $4, b)$.

С учетом того, что размер изолирующей области полученной на двухслойной задающей маске толщиной $100 \mathrm{~nm}$ составил $1-4 \mu \mathrm{m}$, т.е. $1 / 4$ квадрата, а её сопротивление при $T=77 \mathrm{~K}$ не менее $150 \mathrm{M} \Omega$, можно констатировать, что сопротивление полученной изолирующей области составляет величину не менее чем $600 \mathrm{M} \Omega$ на квадрат.

Таким образом, в ҮВСО-структурах, полученных методом ЗМ с использованием однослойной маски из аморфного оксида церия толщиной $1.5 \mu \mathrm{m}$ или двухслойной маски с толщиной первого аморфного слоя $100 \mathrm{~nm}$, сопротивление изолирующих областей микронных размеров составляет не менее чем $150 \mathrm{M} \Omega$ на квадрат при $T=77$ К, что является достаточным для приборных применений таких структур, в частности, в схемах с большим числом элементов [10].

\section{5. Заключение}

Метод ЗМ позволяет с использованием стандартной фотолитографии уверенно изготавливать сверхпроводящие элементы на основе пленок YВСО с шириной полоска $2 \mu \mathrm{m}$ и электрофизическими параметрами, достаточными для приборных применений. При этом раз- 
брос плотности критического тока тестовых мостиков шириной от 2 до $10 \mu \mathrm{m}$ не превышает $10 \%$, а разброс температуры сверхпроводящего перехода $-0.5 \mathrm{~K}$.

Сопротивление изолирующих областей микронных размеров, полученных методом задающей маски из аморфного оксида церия, составляет величину не менее чем $150 \mathrm{M} \Omega$ на квадрат при $T=77 \mathrm{~K}$ и является достаточным для приборных применений таких структур.

\section{Финансирование работы}

Исследование выполнено при финансовой поддержке РФФИ в рамках научного проекта № 20-08-01006. В работе использовалось оборудование ЦКП ИФМ РАН „Физика и технология микро- и наноструктур“.

\section{Конфликт интересов}

Авторы заявляют, что у них нет конфликта интересов.

\section{Список литературы}

[1] E. Il'ichev, L. Dörrer, F. Schmidl, V. Zakosarenko, P. Seidel, G. Hildebrandt. Appl. Phys. Lett. 68, 708 (1996).

[2] M.I. Faley, U. Poppe, K. Urban, V.Yu. Slobodchikov, Yu.V. Maslennikov, A. Gapelyuk, B. Sawitzki, A. Schirdewan. Appl. Phys. Lett. 81, 2406 (2002).

[3] W. Lang, M. Marksteiner, M.A. Bodea, K. Siraj, J.D. Pedarnig, R. Kolarova, P. Bauer, K. Haselgrübler, C. Hasenfuss, I. Beinik, C. Teichert. Nucl. Instrum. Meth. Phys. Res. 272, 300 (2012).

[4] M. Malnou, C. Feuillet-Palma, C. Ulysse, G. Faini, P. Febvre, M. Sirena, L. Olanier, J. Lesueur, N. Bergeal. J. Appl. Phys. 116, 074505 (2014).

[5] Д.В. Мастеров, С.А. Павлов, А.Е. Парафин, П.А. Юнин. ПЖТФ 42, 11, 82 (2016).

[6] Д.В. Мастеров, С.А. Павлов, А.Е. Парафин, Л.С. Ревин, А.Л. Панкратов. Патент РФ на полезную модель № 188983 (2019).

[7] Д.В. Мастеров, С.А. Павлов, А.Е. Парафин, Е.В. Скороходов. ФТТ 62, 9, 1398 (2020).

[8] Д.В. Мастеров, С.А. Павлов, А.Е. Парафин, П.А. Юнин. ЖТФ 90, 10, 1677 (2020).

[9] Д.В. Мастеров, С.А. Павлов, А.Е. Парафин, Е.В. Скороходов, П.А. Юнин. ФТТ 60, 11, 2100 (2018).

[10] A.M. Klushin, M. He, M.Yu. Levitchev, V.V. Kurin, N. Klein. J. Phys. Conf. Ser. 97, 012268 (2008).

Редактор Е.Ю. Флегонтова 